\title{
The Digital Economy and Its Impact on Consumption in the Regions of Bulgaria
}

\author{
Olga Mancheva-Ali \\ Tourism Department of Faculty of Economics \\ University of Veliko Tarnovo "St. Cyril and St. Methodius" \\ Veliko Tarnovo, Bulgaria \\ o.mancheva@ts.uni-vt.bg
}

\begin{abstract}
Digitalization is the basis for the development of a modern economy, and this process covers all aspects of management, including consumer behavior in the environment. This article discusses the digitalization of the economy in the regions of Bulgaria and focuses on the presentation and analysis of the current data of European and national statistics in connection with digitalization in Bulgaria and describing the important processes and trends in this process. All this is done with an emphasis on the tourism industry as an important part of the service sector and a high share in the formation of the country's gross domestic product. The analysis of the integration of digital technologies in Bulgaria and the EU, data of online sales, the use of Internet services, online ordering of travel services, digital skills of human resources. The data shows that Bulgaria lags behind in the digitalization of its economy, and this affects consumer behavior, which, in turn, generates mistrust and accumulates negative experiences for various reasons. Despite these negative trends, in the context of a global pandemic, the digitalization of the economy is proving to be an inevitable process, and Bulgarian enterprises and consumers are paying more and more attention to all tools and means of digital supply and consumption.
\end{abstract}

Keywords-digitalization, technology, economy, tourism industry.

\section{INTRODUCTION}

The whole process of the so-called "Digital transformation" includes many activities related to the introduction of modern technologies, innovative platforms for information processing, digital marketing and advertising. [1] The digitalization of the industrial sectors in Bulgaria and the development of a data-based economy is one of the goals in the national program "Digital Bulgaria 2025". This program, supported by the European Structural Funds, outlines measures to promote the digitalization of enterprises.

According to the Concept for digital transformation of the Bulgarian industry (Industry 4.0), the digital economy includes diverse activities, business models and technological solutions. It is related to the development of e-business and e-commerce, automated industrial production and intelligent manufacturing enterprises, intelligent transport systems and vehicles, intelligent energy systems and others. Cloud technologies, the Internet of Things, technologies for processing large databases, robotics, artificial intelligence are among the main prerequisites for the development of the digital economy. In the tourism industry, Tourism 4.0 leads to increased consumer satisfaction and stimulates the growth of tourist flows. [2]

As part of the European Union, the Bulgarian economy is subject to the European legal framework, but has its own identity and characteristics of the economic processes that should be considered and analysed.

The official data for Bulgaria are the following: [3]

The total area is $110,371.9$ square kilometers

Population: 7000039 inhabitants (as of December 31, 2018), of which 5159129 inhabitants $(73,7 \%)$ in the cities;

Age structure: $0-14$ years $-14,4 \%, 15-64$ years $-64,3 \%$, $65+$ is $21,3 \%$;

Population density: 63,4 people/sq. km;

Administrative division: 6 level 2 regions (NUTS2), 28 districts, 265 municipalities, 5256 settlements (as of 31.12.2018), 257 cities, 4999 villages

Communication and transport network - density of the road network: $0.18 \mathrm{~km} / \mathrm{km} 2$

Mineral springs: 148 deposits

World cultural and natural heritage:

- Protected territories - 5,3\% of the country's territory;

- $\quad$ Protected areas under NATURA 2000 - 34,9\% of the country's territory;

Cultural heritage sites - 7 pieces, 5 elements of the intangible cultural heritage, 2 good practices in the UNESCO Register of good practices - natural heritage sites - 3 pieces.

The purpose of this report is to present the current picture of the processes related to the implementation and consumption of digital products and services on the example of Bulgaria, with a focus on digitalization in the tourism industry.

\section{Tasks:}

- Presentation and analysis of current data from European and national statistics in connection with the processes of digitalization in Bulgaria; 
Presentation of the processes of digitalization in the tourism industry;

- $\quad$ Outlining important trends for the development of digitalization in Bulgarian enterprises.

To perform these tasks, information on the digital transformation of business and digital consumption in general and in tourism is collected, analyzed and presented.

\section{METHODS}

The process of digitalization is dynamic, diverse and affects various subjects and objects of the economy. Its main task can be defined as the desire of the companies to increase their competitiveness through the implementation and use of computer solutions. The purpose is to organize, manage and control through digital means, but also to form new behavioural approaches aimed at deciding how to use and/or purchase products and services from consumers.

Digitalization contributes to the creation of new processes of interaction between buyer and seller in the virtual environment, and hence to streamline management decisions, consistent with the dependence "resources - capabilities results" based on strategic, program-target approach and analysis "costs - effects", which is leading in management. [4] Digitization should also be seen as a way to optimize resources, processes and interaction between users and suppliers

This analysis includes data mainly from the National Statistical Institute (NSI) of Bulgaria, as well as from the reports on the index for the penetration of digital technologies in the economy and society of the European Commission. Data related to the digital transformation of Bulgaria from the point of view of business and consumers as well as the processes of digitalization of the tourism industry.

Trends and measures in the field of digitalization are analysed in Bulgaria. Statistical, analytical and descriptive methods were used.

\section{MAIN PART}

3.1. Digital transformation in Bulgaria from the point of view of business

Since 2014, the European Commission has been monitoring the progress of EU members in the field of digital technologies, after which the data are published in the Reports on Indices for the Introduction of Digital Technologies in the Economy and Society (DESI). The current COVID-19 pandemic has shown how important digital assets are to the economy and how networks, connectivity, data, etc., as well as basic and in-depth digital skills, support economies and societies by allowing work to continue at a distance.

The report on DESI for 2020 includes an analysis at European level of broadband, digital skills, internet use, digitalization of enterprises and digital public services, emerging technologies, cybersecurity, the ICT sector and its costs for research and development, as well as the use by Member States of Horizon 2020 funds. [5] Table 1 shows the progress of our country compared to the EU averages, as the data for 2020 are not final.
TABLE I. DATA ON THE PENETRATION OF DIGITAL TECHNOLOGIES IN THE ECONOMY AND SOCIETY, INCLUDING ALL INDICATORS FOR THE DIGITAL ECONOMY OF BULGARIA AND THE EU FOR 2018, 2019 AND 2020

\begin{tabular}{|c|c|c|}
\hline Year & Bulgaria & EU \\
\hline $\mathbf{2 0 2 0}$ & 36,4 & 52,6 \\
\hline $\mathbf{2 0 1 9}$ & 33,8 & 49,4 \\
\hline $\mathbf{2 0 1 8}$ & 33,5 & 46,5 \\
\hline
\end{tabular}

Comment: The data are in $\%$ and for 2020 are not final

Source: DESI

Bulgaria ranks last among the $28 \mathrm{EU}$ member states in the European Commission's DESI entry index for 2020. Despite the increased overall score to $36.4 \%$, today the country ranks last behind on the basis of data obtained before the pandemic.

On the topic of the introduction of digital technologies, the figures are identical and again our country ranks last among the EU member states. (Table 2)

TABLE II. INTEGRATION OF DIGITAL TECHNOLOGIES IN BULGARIA AND THE EU FOR 2018, 2019 AND 2020

\begin{tabular}{|c|c|c|}
\hline Year & Bulgaria & EU \\
\hline $\mathbf{2 0 2 0}$ & 17,9 & 41,4 \\
\hline $\mathbf{2 0 1 9}$ & 16,9 & 39,8 \\
\hline $\mathbf{2 0 1 8}$ & 18,3 & 37,8 \\
\hline
\end{tabular}

Comment: The data are in $\%$ and for 2020 are not final

Source: DESI

The Bulgarian companies find it difficult to take advantage of the opportunities provided by online commerce such as:

- $7 \%$ of SMEs sell online, compared to an EU average of $18 \%$;

- 3\% of all SMEs in the country realize cross-border sales and only $2 \%$ of their turnover is from online trade;

- $10 \%$ of businesses use social media to promote their business, compared to an EU average of $25 \%$;

On the positive side, $23 \%$ of companies share information online, with an EU average of $34 \%$.

In today's pandemic environment and a number of governments' restrictions on business and consumers, digital transformation is proving to be a key factor in economic development and a means of creating alternative opportunities for all stakeholders.

\subsubsection{Data on software business solutions applied in the} Bulgarian economy

As an example of one of the most applicable business systems can be mentioned 2 main - Enterprise Resource Planning (ERP) and Customer relationship management (CRM). The first (ERP) take into account the industry specifics of the enterprise and contribute to increasing the economic efficiency of production. They are actively supported and work in good sync with customer relationship management systems - CRM. Customer relationship management software automates and integrates sales and marketing functions within the organization. Therefore, CRM can be a standalone application or a special module within an ERP system.

The level of usability of these systems in Bulgaria can be traced in Figure 1. [6] 


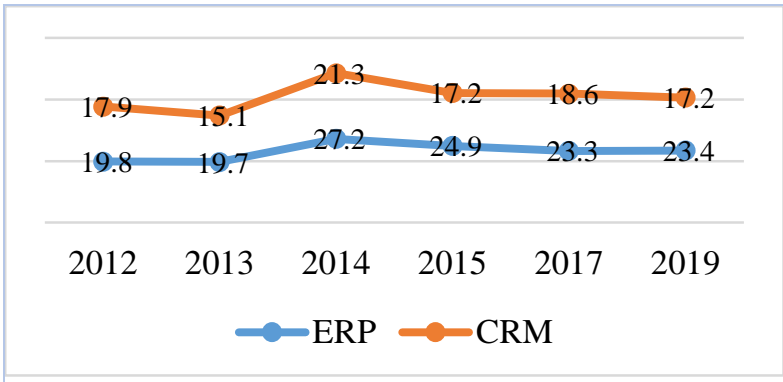

Source: NSI

Comment: Data is in\%

Fig. 1. Data on the proportion of enterprises in Bulgaria using ERP and CRM systems for the period 2012-2019

From these data, higher percentages are observed for both types of systems in 2014, after which there is a decrease in the use of ERP systems by $4,1 \%$ and CRM by $3,8 \%$. The reasons for reducing the consumption of these systems vary from company to company, but if we look at the potential external factors of companies, this decline may be due to the completion of EU operational programs to stimulate business to implement computer systems and technologies.

Regarding the size of the enterprises that implemented the above systems in 2019, we can summarize that:

- Most ERP systems are used in large enterprises (250+ employees) with a share of $60,7 \%$. In medium-sized enterprises (50-250 employees) is $40,1 \%$, while in small enterprises (10-49 employees), the data show 19,2\% usability;

- The use of CRM systems in large enterprises reaches $34,1 \%$, in medium enterprises this share is nearly $30 \%$, and the lowest percentage of usability, the systems in small enterprises have $15,3 \%$.

The digitalization of business is an important step towards modernization, but it is more important for businesses to realize this.

\subsubsection{Data on companies selling online in Bulgaria}

The National Statistics of Bulgaria also contains data on the topic that outlines the real situation of digital consumption, containing information on received online orders for products and/or services to Bulgarian suppliers who have positioned their business offer online. The data can be traced in Table 3 .

TABLE III. INTEGRATION OF DIGITAL TECHNOLOGIES IN BULGARIA AND THE EU FOR 2018, 2019 AND 2020

\begin{tabular}{|c|c|c|c|c|c|}
\hline Year & $\mathbf{2 0 1 5}$ & $\mathbf{2 0 1 6}$ & $\mathbf{2 0 1 7}$ & $\mathbf{2 0 1 8}$ & $\mathbf{2 0 1 9}$ \\
\hline \multicolumn{6}{|c|}{ By size of enterprises /number of employees/: } \\
\hline $10-49$ & 8,1 & 7,9 & 9,5 & 7,2 & 10,0 \\
\hline $50-249$ & 11,2 & 11,2 & 14,6 & 11,5 & 14,9 \\
\hline $250+$ & 14,4 & 17,4 & 18,5 & 15,4 & 18,0 \\
\hline Total & $\mathbf{8 , 7}$ & $\mathbf{8 , 6}$ & $\mathbf{1 0 , 5}$ & $\mathbf{8 , 1}$ & $\mathbf{1 0 , 9}$ \\
\hline
\end{tabular}

Comment: Data is in\%

Source: NSI

It can be noted that in the last 5 years there has been no significant dynamics in online orders, and if we judge only from this source of information, we would say that online commerce has a relatively stable indicator with a slight growth of $2,8 \%$ in 2019.

\subsection{The process of digitalization in Bulgaria from the point of view of consumers}

From the point of view of the consumption of digital services, a significant part relates to Internet services (table 4).

TABLE IV INTEGRATION OF DIGITAL TECHNOLOGIES IN BULGARIA AND THE EU FOR 2018, 2019 AND 2020

\begin{tabular}{|c|c|c|}
\hline Year & Bulgaria & EU \\
\hline $\mathbf{2 0 2 0}$ & 36,6 & 58,0 \\
\hline $\mathbf{2 0 1 9}$ & 36,7 & 55,0 \\
\hline $\mathbf{2 0 1 8}$ & 34,1 & 51,8 \\
\hline
\end{tabular}

Comment: The data are in\% and for 2020 are not final

Source: DESI

The table contains information about various activities that can be performed on the Internet, some of which are sales, shopping, use of the Internet for information and more. From the detailed data it is clear that Bulgaria is in the penultimate place in terms of the use of Internet services, as the overall result is well below the EU level: $67 \%$ of Bulgarians use the Internet (in the EU the average is $85 \%$ ), while $24 \%$ never they have not used it - this is the highest value in the whole EU.

Of the total percentage for 2020 in Bulgaria, 31\% of consumers use the Internet for shopping and $13 \%$ for online sales.

From the data presented so far, it is evident that the level of digitalization of Bulgarian enterprises is one of the lowest in the EU. Of course, this also affects consumer behavior, which indicates avoiding transactions and online purchases.

Apart from the low level of digitalization of Bulgarian enterprises, there are other reasons why consumers avoid online transactions. In this regard, the NSI published information (2019) according to which $37,1 \%$ of users use the Internet as a source of information about goods and services, and the main reason why consumers do not want to shop online is that they prefer to see on-site product or service $(31,4 \%)$.

From data on the site of NSI it turns out that the problems that identify consumers in online shopping are in several areas (Table 5).

TABLE V. PROBLEMS ENCOUNTERED IN PURCHASING GOODS AND SERVICES ONLINE IN BULGARIA FOR 2019

\begin{tabular}{|c|c|}
\hline Types of problems & $\mathbf{\%}$ \\
\hline $\begin{array}{c}\text { Technical damage to the website during ordering or } \\
\text { payment }\end{array}$ & 3,8 \\
\hline $\begin{array}{c}\text { Difficulty finding information on warranties and other } \\
\text { legal rights }\end{array}$ & 5,0 \\
\hline $\begin{array}{c}\text { Delivery time is longer than specified } \\
\text { price, unexpected transaction fee) }\end{array}$ & $\mathbf{8 , 7}$ \\
\hline $\begin{array}{c}\text { Final costs are higher than indicated (eg higher delivery } \\
\text { Wrong or damaged goods have been delivered }\end{array}$ & 4,6 \\
\hline $\begin{array}{c}\text { Problems related to fraud (eg goods / services not } \\
\text { received at all, financial losses due to misuse of your } \\
\text { credit card data, etc.) }\end{array}$ & 0,5 \\
\hline $\begin{array}{c}\text { Difficulties in filing a complaint and claiming } \\
\text { compensation or receiving an unsatisfactory response } \\
\text { after a complaint has been lodged }\end{array}$ & 1,8 \\
\hline $\begin{array}{c}\text { Foreign merchants do not work with Bulgaria (eg do not } \\
\text { accept orders or payment cards from other countries) }\end{array}$ & 1,5 \\
\hline Others & 3,4 \\
\hline Comment: Data is in\% &
\end{tabular}

Source: NSI 
It turns out that one of the most common problems is noncompliance with the delivery time of the product, followed by difficulties in finding information about warranties and other legal rights as well as delivered incorrectly or damaged goods.

Examples can be given with other sectors that are being digitized. For example, national electricity markets have low levels of competition and asymmetry in the degree of liberalization between them, which is a serious problem for closer EU integration [7].

\subsection{Digitalization in the tourism industry}

Digitalization brings competitiveness of enterprises and creates a modern look of the processes taking place in them. The Tourism Committee of the Organization for Economic Co-operation and Development states: "The future of traditional destinations will depend on a more innovationoriented tourism policy" with investments in "innovation mechanisms" and "innovation promotion programs", that can facilitate the necessary innovations in the product, process and marketing levels"[8], and as we know "innovation is a solution that can bring profits." [9]

An example of inovation and the growing concern for sustainable development is the EU's reformed agricultural policy in 2013, which supports the standard of living of farmers while respecting animal welfare, environmental protection and food safety rules, and last but not least sustainable rural development. [10]

According to the methodology of the NSI, the services sector is formed by trade, repair of motor vehicles, personal and household goods, hotels and restaurants, transport, storage and communications, financial intermediation, real estate and business services, public administration and compulsory social security, education, healthcare, social activities and other activities.

The tourism sector, as part of the services sector, is related to the production and sale of various tourism products and services. The economic and social potential of tourism, which worldwide generates an average of over 11-12\% of GDP, predetermines the creation of new business models, new forms of service and communication with customers and business partners. This is done through the continuous application of innovative approaches and at the present stage requires technological transformation through digitalization. [11].

An integrative approach is needed in three main areas:

First, digitization and automation of basic and additional travel services and the use of smart technologies such as: NFC technologies, digital realities, beacon and blockchain technologies, artificial intelligence, the Internet of Things, cloud technology, innovative software solutions such as: directional sound, Li-Fi or optical method for wireless data transmission, Plug \& Play technology, fast 5G network, etc.

Second, the use of tools to maintain a good image of accommodation and tourist destinations or tourist destinations in general on the Internet through activity in social networks, monitoring the degree of satisfaction of tourists, expressed through the online reputation created through reservation systems and sites for sharing opinions from travel, using revenu management to create a sense of bargaining and fairness, etc.

Third, innovative approaches to tourism management through the use of large data sets (Big data) by public authorities and private organizations in the preparation of strategies, innovative techniques in the selection of staff for the tourism industry, digitalization of public services, transport, cultural and historical heritage, attractions, etc.

Digitalization in tourism is a process that is characterized by dynamics and diversity of events, as well as a high level of competition, while striving to offer maximum satisfaction to its customers.

The extent to which the Bulgarian consumer chooses online travel services can be seen in published data of the national statistic. The information contains data on travel or hotel reservations (Table 6).

TABLE VI. TOURIST SERVICES ORDERED ONLINE IN BULGARIA FOR THE PERIOD 2015-2019

\begin{tabular}{|c|c|c|c|c|c|}
\hline $\begin{array}{c}\text { Years / } \\
\text { Services }\end{array}$ & $\mathbf{2 0 1 5}$ & $\mathbf{2 0 1 6}$ & $\mathbf{2 0 1 7}$ & $\mathbf{2 0 1 8}$ & $\mathbf{2 0 1 9}$ \\
\hline $\begin{array}{c}\text { Hotel } \\
\text { reservations and } \\
\text { tourist packages }\end{array}$ & 26,1 & 18,3 & 20,4 & 19,1 & 20,7 \\
\hline $\begin{array}{c}\text { Preparation for } \\
\text { travel (tickets, car } \\
\text { rental, etc.) }\end{array}$ & 16,0 & 13,0 & 10,9 & 8,7 & 10,2 \\
\hline Total & $\mathbf{4 2 , 1}$ & $\mathbf{3 1 , 3}$ & $\mathbf{3 1 , 3}$ & $\mathbf{2 7 , 8}$ & $\mathbf{3 0 , 9}$ \\
\hline
\end{tabular}

Comment: Data is in $\%$

Source: NSI

The table shows that in 2019, tourist services ordered online increased by $3,1 \%$ compared to the previous year, but compared to 2017 there is a total decrease of $0,6 \%$.

In the general picture of consumption for the considered period, the best positioning of online consumption of tourist services is in 2015, as the decrease compared to 2019 is by $11,2 \%$.

In a general comparison of online consumption (figure 2), tourist services have a relatively good positioning.

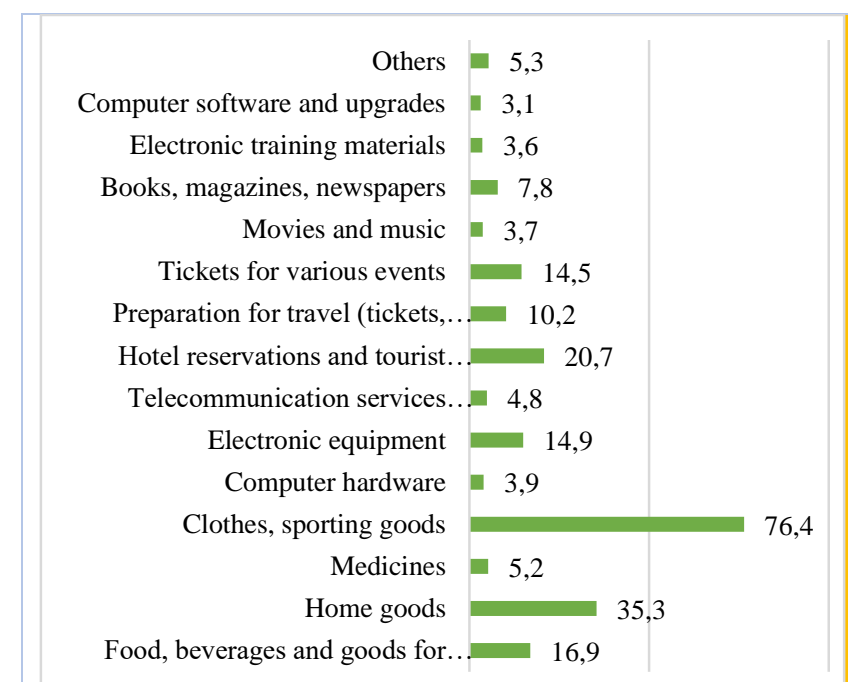

Comment: Data is in\%

Source: NSI

Fig. 2. Type of goods and services ordered by users on the Internet for 2019 
It turns out that most online orders are made for clothing and sporting goods, followed by household goods, and in third place are travel and hotel reservations.

From the statistical data it can be judged that the process of digitalization has reached certain levels, but it is difficult to predict the forthcoming dynamics of consumption by tourists. At the forefront is consumer confidence in the supply of tourism products and services, as well as the level of digitalization of business. So this dependence is still under construction and subsequent analysis, even more so in the dynamic conditions of a global pandemic.

\subsection{Trends in the development of digitalization}

The contribution of digitalization to the economy can be considered in two directions: [12]

- Contribution at the expense of information technology growth, relating to the contribution to production, employment, export earnings, etc. due to the production of goods and services related to information technology;

Contribution to the dissemination of information technology, refers to the development induced by information technology through increased productivity, competitiveness, growth and human activity well-being due to the spread of this technology in various sectors of the economy and society.

These two contributions show the link between information technology and consumers, and several new trends emerging from the digitalisation process, respectively:

increasing the direct sales of the client;

- $\quad$ increasing the number of new intermediaries such as Internet portals specializing in the sale of products and services;

ensuring expanded access of users to the channels for dissemination of information;

providing a flexible opportunity to adapt products and services to the needs and expectations of consumers;

- increasing the transparency and efficiency of the relationship between consumers and business.

- Changing consumer behavior and raising their expectations for better services.

However, increasing distribution channels is a serious challenge for businesses, including the tourism industry. Cooperation is required both between the different sectors of the economy and between the different directions in the tourism business - tourism companies, intermediary companies, transport companies and other.

And no matter how much we talk about digitalization, the process cannot happen without one main factor, namely human resources. It turns out that communication and networking skills are essential for business, as they require specialized knowledge and the ability to analyse based on large amounts of information.

In the field of human capital, Bulgaria ranks 26th out of 28 EU countries, moving two places ahead of 2019. However, its result of 33,9\% remains well below the EU average of $49 \%$. The overall level of basic digital skills in Bulgaria is among the lowest in the EU (table 7).
TABLE VII. DATA ON DIGITAL SKILLS OF HUMAN RESOURCES IN BULGARIA AND THE EU FOR 2018, 2019 AND 2020

\begin{tabular}{|c|c|c|}
\hline Year & Bulgaria & EU \\
\hline 2020 & 33,9 & 49,3 \\
\hline 2019 & 28,5 & 47,9 \\
\hline 2018 & 31,7 & 48,6 \\
\hline
\end{tabular}

Comment: The data are in\% and for 2020 are not final

Source: DESI

The report also shares data that the share of people with basic skills in the field of digital technologies amounts to about $29 \%$ of the Bulgarian population aged 16 to 74, while the EU average is $58 \%$. Only $11 \%$ of people have above-basic skills, which is one third of the EU average.

At present, ICT professionals account for 3\% of total employment, which is an increase, although this figure continues to represent a small share of the workforce given the labor shortage in the labor market. Women ICT professionals make up only $1,8 \%$ of total employment, which is slightly above the EU average.

\subsection{Measures to achieve a higher level of digitalization} in Bulgaria

The Council of Ministers of Bulgaria has approved the strategic document "Concept for Digital Transformation of Bulgarian Industry (Industry 4.0)" as a starting point for developing a strategy for Bulgaria's participation in the fourth industrial revolution until 2030. Working group including representatives of the Ministry of Economy, employers' organizations and the ICT sector is in the process of finalizing the strategy.

The measures and objectives in the Concept aim to provide a basis for the development of a strategy for SMEs and a research and innovation strategy (RIS3), and in both strategic documents digitization is a cross-cutting priority. The strategy paper sets out three priorities:

- $\quad$ strengthening the link between science and industry and accelerating integration into European and international programs in line with the development and implementation of the "Industry 4.0" concept;

- promotion of technological innovations in the Bulgarian economy;

building human, scientific, organizational and institutional capacity for the development of "Industry 4.0" in Bulgaria.

In addition to the above concept, the digitalization of industrial sectors in Bulgaria and the development of a databased economy is one of the goals in the national program "Digital Bulgaria 2025" from 2019.

Regarding the tourism industry, it is important to say that the European Commission focuses its support for tourism on four groups of initiatives: [13]

- improving the business environment and increasing investment in the tourism sector by making better use of available EU funding opportunities;

- enhancing the digitization and use of online tools within the industry to meet new trends and consumer expectations. 
- Improving the skills and competencies of the tourism sector in order to improve career prospects and support the industry;

- Raising the profile of Europe as a tourist destination in order to complement promotional efforts at national and regional level and attract more tourist flows to Europe, especially from major third country markets.

In tourism, the digitalization process started with an increase in the number of airlines and the emerging need for digital services. Today tourism can be defined as a sector with many online platforms, that combine the provision of services and those for managing and organizing activities.

\section{CONCLUSION}

Technological improvement covers activities for introduction of new technologies or improvement of existing ones. [14]

The digital economy is part of economic activities, business models and technological solutions. It creates preconditions for modernization and increasing the competitiveness of enterprises.

Digital solutions are many and varied. Mainly large enterprises in Bulgaria implement software solutions for business management. Examples are ERP and CRM.

The real situation in the Bulgarian economy is lagging behind in the implementation and use of digitalization in its business, but in a global pandemic, the process is becoming more dynamic and sought after. The slowdown in digitalization in enterprises has a negative trend in terms of consumer demand and use of digital purchasing solutions. When the business does not have established habits for digital relationships with consumers, there is an increase in consumer distrust. It is important for the business to realize that the communication between it and the consumers undergoes remodeling and it is already done electronically. [15]

In addition to the listed challenges to the digitalization process, there is another important factor, namely human resources, without which we cannot talk about a full-fledged proces

In the Bulgarian economy, and in particular in the tourism industry, there are intensive processes related to the digital transformation. A serious factor in today's conditions is the global pandemic and the number of restrictions imposed by governments on business and consumers that need to be introduced. The expectation for the digital transformation is to create funds for alternative opportunities for business and consumers.

\section{REFERENCES}

[1] M. Baker, Digital Transformation, 2014. URL: https://dga.or.th/upload/download/file_8f093d6d5522a1286dd23b4ee 3d65d84.pdf (accessed 10.11.2020).

[2] D. Varadzhakova, "Tourism 4.0 - Technological Transformation and Digitalization" in Ribov (ed.), The Challenges of the New Technological Transformation - Proceeding of XXV Symposium "Quality, Competitiveness, Sustainable Development", Avangard Prima, Sofia, 2018, pp. 311-246.

[3] National Concept for Spatial Development (NCDP), which is for the period 2013-2025, Sofia, 2020. URL: https://www.eufunds.bg/bg/oprd/node/4554 (accessed 10.11.2020).
[4] S. Dimitrova, Management of Defense Resources in the Security Sector, Publishing House at the Vasil Levski National High School, 2011, p. 184.

[5] Report on the Index of Digital Entry into the Economy and Society (DESI), Bulgaria, 2020. https://ec.europa.eu/digital-singlemarket/en/scoreboard/bulgaria Report on the Index of Digital Entry into the Economy and Society (DESI), Bulgaria, 2020. URL: https://ec.europa.eu/digital-single-market/en/scoreboard/bulgaria (accessed 10.11.2020).

[6] National Statistical Institute of the Republic of Bulgaria. URL: www.nsi.bg (accessed 22.10.2020).

[7] N. Byanova, The single electricity market - opportunity and reality, Applying an integrated approach to the economic policy of the European Union, I\&B, 2017, pp. 72-104.

[8] European Commission, Thematic guidance for tourism investments URL: https://ec.europa.eu/regional_policy/bg/policy/themes/tourism/ (accessed 10.11.2020).

[9] V. Tsanevska, Business angels as a source of innovation funding", VII International Scientific and Practical Conference "Innovation in Technology and Education”, Belovo - Veliko Tarnovo, 2014, p. 146.

[10] I. Byanov, The Common Agricultural Policy and Bulgaria, in: Application of an Integrated Approach in the Economic Policy of the European Union, Veliko Tarnovo, I\&B, 2017, p. 21.

[11] D. Varadzhakova, Theoretical and Methodological Aspects of Smart Tourism Destinations Competitiveness, Proceedings Jubilee International Scientific Conference "Tourism - Beyond Expectations", UNWE, Sofia, 2020, pp. 435-446.

[12] D. Shanker, "ICT and Tourism: Challenges and Opportunities", Conference on Tourism in India - Challenges Ahead, Part I - Tourism Strategy, IIMK 58, 2008, pp. 51-53.

[13] D. Shanker, "ICT and Tourism: Challenges and Opportunities", Conference on Tourism in India - Challenges Ahead, Part I - Tourism Strategy, IIMK 58, 2008, pp. 51-53.

[14] The Information and Communication Technologies. URL: https://www.semanticscholar.org/paper/ICT-and-Tourism\%3AChallenges-and-Opportunities-

Shanker/111eeabb4c758252fc3a507969ec74ec9b53300d (accessed 10.11.2020) (accessed 10.11.2020).

[15] OECD Digital Economy, 2017, p. 35. URL: https://www.oecd.org/digital/oecd-digital-economy-outlook-20179789264276284-en.htm (accessed 10.11.2020).

[16] V. Statev, Economics of Tourism, Faber Publishing House, Veliko Tarnovo, 2007, p. 18.

[17] N. Kostadinova, Digital Marketing - A Strategy for Positioning Hotels with Specific Target Markets Jubilee, International Scientific Conference Economic science, education and real economy, development and development, Varna, 2020, vol. III, p. 704. 